\title{
The Attitudes of Victims of House-breaking on their being Victimized in Sri Lanka
}

\author{
Prof. M.W. Jayasundara \\ Department of Criminology and Criminal Justice, University of Sri Jayewardenepura, Sri Lanka
}

\begin{abstract}
As a developing country, Sri Lanka faces many problems, and presently they show an increasing trend. Among them, social disparities, terrorism, traffic in illegal narcotics, and crime are predominant. The term 'housebreaking, in Sri Lanka is similar to 'burglary' in other countries. After 2015, the definition of housebreaking and theft had been changed to 'house breaking' as the term implies theft is included in housebreaking. This study draws on the housebreaking rates prevalent in Sri Lanka from 2006 to 2020, which records a considerable decrease in the number of housebreaking from 95.7 in 2006 to 30.7 in 2020. The research problem is primarily concerned with the impacts of house-breaking as a property crime, and how far it has affected the normal life of the citizens of the country as it stands at $20.9 \%$ of the total number of grave crimes of the country. Therefore, this study was aimed at finding the nature and the impacts of housebreaking on victims. Sixty victims of the housebreaking were selected to achieve the targets of the study from a convenient sample, adding 1-9 housebreaking from a police station chosen from selected eight districts. The data were collected by using a semi-structured interview schedule administered to the victims of housebreaking. The findings of the study revealed that the many house-breakers were unknown to the victims except the fact that $18.3 \%$ of offenders were their relatives and neighbours. The majority $63.4 \%$ of the victims were involved in businesses and government sector employment and comparatively, they were rich people in the community to be targeted by the offenders for house-breaking. The main target of the burglars was the money and gold on some occasions they had stolen mobile phones, television and other household electronics items. The victims had identified $30 \%$ of the housebreakers and they were drug addicts and alcoholics who had committed burglary to finance their drugs. The impact of the housebreaking was financial loss, mental pain and anxiety caused to the majority of the victims. The victims have taken measures to prevent revictimization by ensuring security of their residences as well as of their valubels. The study proposes reducing drug addiction and target hardening on burglars would minimize the house-breaking of the country.
\end{abstract}

Key words: Housebreaking, Victims, Burglary, Perpetrators, valubels

\section{INTRODUCTION}

$\mathrm{T}$ he term house-breaking is defined as the crime of entering a building to steal. According to the legal definition of house-breaking, it is an act of crime through which one breaks the house of another person to commit a crime therein. In Sri Lanka, the term 'house-breaking is used in the place of burglary as in western countries. Accordingly, the 431 clause of the Penal Code of Sri Lanka defines house-breaking as an act that commits by a person who commits house-trespass if he affects his entrance into the house or any part of it in any of the six ways of the following;

i) If he enters or quits through a passage made by himself, or by any abettor of the house-trespass in order to commit house-trespass.

ii) If he enters or quits through any passage not intended by any person, other than himself or an abettor of the offence, for human entrance; or through any passage to which he has obtained access by scaling or climbing over any wall or building.

iii) If he enters or quits through any passage which he or any abettor of the house-trespass has opened in order to commit house-trespass, by any means by which that passage was not intended by the occupier of the house to be opened.

iv) If he enters or quits by opening any lock to commit house-trespass or in order to quit the house after the house-trespass.

v) If he effects his entrance or departure by using criminal force or committing an assault or by threatening any person with assault.

vi) If one enters or quits by any passage which he knows to have been fastened against such entrance or departure and to have been unfastened by himself by an abettor of the house-trespass.

House-breaking has occurred since people started to demarcate and protect their personnel properties themselves and it has been considered a very serious crime because the house is deemed to be a place of sanctity for individuals and family. Although house-breaking was once considered as breaking into a house at nighttime to commit a crime now it is considered as any unlawful entry, whether forceful or not and regardless of the time of the day. People consider housebreaking an act of taking some valuable property or money from a victim at their home by theft, force, violence or threat of violence. Punishment is meted out to the perpetrators of this crime according to nature and the gravity of its impact. However, victims of house-breaking experience anger, fear, and a sense of invasion of privacy and vulnerability, in addition to their financial loss.

House-breaking has a long history of humankind as found in Hammurapi's Code, Roman law, and other laws of the AngloSaxon kings. Accordingly, house-breaking was distinct from mere theft. Unlike the robber, the house-breaker was considered hidden and silent in his purpose because housebreaking and theft are committed without confrontation of the 
victim. Sometimes offenders use weapons such as knives and other sharp instruments or firearms to threaten and frighten their victims if they are present at the time of house-breaking and also as a means to escape confrontation with the victim or to avoid capture.

According to Wright and Decker (1994) who interviewed 105 active burglars revealed that burglars or house-breakers committed various offences other than mere theft. Yet most of them had considered house-breaking their preferred crime as it offerred them greatest chance of success with minimum risk. Many house-breakers were poor, socially run-down and lived in disorganized areas where poverty was rifen. They were uneducated, unreliable and resistant to orders, and many were from single-parent homes. House-breakers are motivated to commit crime to fulfil their immediate financial requirements and also to meet out rising cost of living. Further, they found psychic rewards committing the housebreaking or burglaries a secondary benefit as an "adventure", "a challenge", or "fun". However, many house-breakers spend the money that they illegally earn on drugs, alcohol and sex. Consequently, they are reluctant to engage in legitimate employments as they are unable to earn money as much as they earn from house-breaking (Rengert and Wasilchick, 2000).

In selecting targets for house-breaking, offenders are often concerned with target exposure, guardianship, target attractiveness and proximity (Maybe, 2001:p. 29). Target exposure refers to the visibility and accessibility of the house while guardianship refers to how well it is protected. In other words, if the house has easy access without being seen by the neighbours and the passers-by and if it does not have any signs of occupancy house-breakers select such targets to find finance through their house-breaking business. Further, target attractiveness refers to the signs of rich pickings available in the house. In other words, the occupants of the house are wealthy or not. Finally, the proximity of the target house is also a concern of the house-breakers. If the target house is located close to their residential area, offenders often select such places.

Unlike in other property crimes in burglary females also participate increasingly. Sometimes, they facilitate perpetration of crimes. Mullins and Wright have discovered that females help their partners to locate potential targets and gain access to homes (2003). Often females commit burglary with others and manage to avoid criminal justice with fewer contacts (Decker, et.al, 1993).

The availability of a professional fence or any person to buy the stolen property is also another concern of the housebreakers. If they can sell the stolen property, they would continue their offence without any challenge (Wales and Hemmens, 2011:438). However, professional house-breakers do not stick to the above mention criteria for their target selection, instead, they may travel miles away in finding attractive targets with careful surveillance and planning. As Shover pointed out experienced burglars are having competence, personal integrity, a specialty in burglary, financial success, and the ability to avoid prison (1992:540549).

There exist different ways of burglarizing as there are several ways of entering houses and crafty maneuver of the entry is gained. It is a fact that victims of house-breaking come from all parts of the island irrespective of geographical location whether it is urban, semi-urban, or rural, and from all walks of life and belong to different races, religions, and social classes. The medium-income and the high-income households are mostly burglarized. Cash, gold, and other valuables are removed and sold at professional fences or pawnshops. It is mentioned that professional house-breakers have their experience know-how and their modus operandi to work on their different problems.

The skilled house-breakers if they are interested in cash they find it through their experience and their anticipation of the behaviour of the victims. When they are in a commercial establishment they know the places where money is kept such as safes, cash drawers, etc. However, in residential homes, the house-breakers' task may be quite difficult as the dwellers often tend to hide their money and valuables such as gold in unexpected places (Barlow, 1978:210).

Criminologists believe that victimization is not a random process. It includes a process encompassing a host of systematic environmental, demographic and personal characteristics. According to the type of crime victims, these characteristics become different. There is a strong possibility that the victims of crime would suffer from mental trauma when he recollects the incident of victimization and he may suffer from distress or shock even throughout one's life. Victimization has a lasting effect of insecurity, fear helplessness, anger, etc. (Paranjape, 2011). Further, victimization may militate not only against the victim but also against the entire community. Therefore, conducting of this research on victims' perceptions and their attitudes on their being victimized would be of considerable significant. Figure 1 indicates a sharp decline in the rates of house-breaking in Sri Lanka after 2006.

Figure 1: House-breaking Rates in Sri Lanka 2006-2016

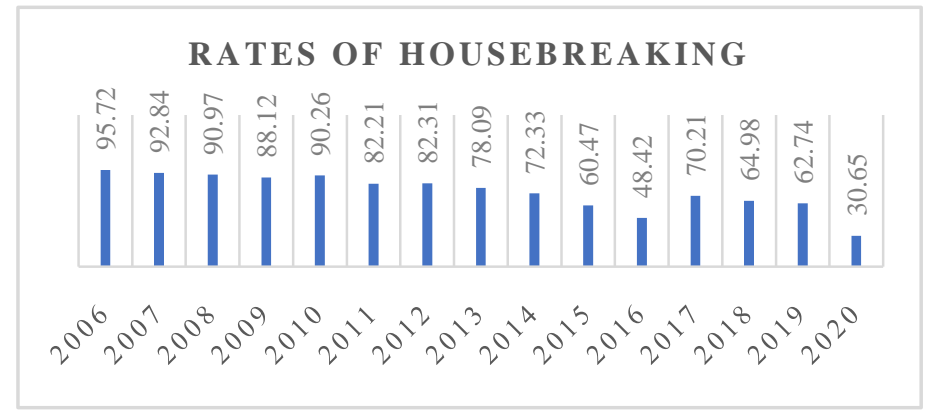

Source: Report of Inspector General of Police 2006-2019

Figure 1 contains statistics of the housebreaking and theft which is reported as a separate type of grave crime in the police report. This type of crime alone comprises $39 \%$ of the 
total number of grave crimes reported in 2019. In 2006, this crime had a portion of $31 \%$ of the total number of grave crimes in that year. This particular change indicates an important trend of changing crime patterns of grave crimes in the country. Even though the proportion of housebreaking and theft has increased compared to that of other types of grave crimes, the rate per 100,000 population indicates a steep decline in the course of the period under consideration. The housebreaking and theft rate remained at 95.7 in 2006 and it declined to 48.4 by 2016 with fluctuation in some years. This decline in housebreaking and theft by 47.3 seems to be a positive sign of a reduction in the criminals and change of that particular criminal behaviour of breaking house and stealing.

\section{Research Problem}

The incidence of house-breaking cannot be perceived as a minor social problem. Such incidents manifest a direct violation of vital social norms and laws of protecting people's property. The laws alone are not sufficient to protect people's property. The social structure together with its organization plays a vital role in the maintenance of peace, law and order in the society, including the protection of victims.

Sri Lankan society has undergone a dramatic change, adversely affecting its social control through cultural and social structural arrangements. The property of people is highly targeted by house breakers as well as by offender gangs. Many valuable items have been stolen causing physical and psychological damages to residential dwellers. Although the police have succeeded in controlling house-breaking to some extent, the unknown house-breakers still keep inflicting injuries upon the law-abiding people and causing loss to their property. This research study mainly concerns this social phenomenon and attempts to explore and explain the incidence of house-breaking and its impacts on the victims of this crime.

\section{Objectives}

- To identify the effects of house-breaking on the victims

- To determine the causes of house-breaking in Sri Lanka

- To determine the nature of house-breakers and the incidence of house-breaking.

\section{Significance of the study}

Although there had been very few researches conducted to determine the nature of the victimization of house-breaking, both the impact of house-breaking on victims and the nature of criminal behaviour of the house-breakers have not yet been examined adequately in Sri Lanka. Therefore, this research will undoubtedly be significant for both academics and policymakers to work towards an extensive program to prevent house-breaking incidents and advance policy planning. The study will also generate new knowledge regarding the criminal behaviour of house-breakers and the causes and motives that lead to committing such crimes.
Further, the impact of house-breaking on the victims and the understanding of the extent of their suffering would help protect and rehabilitate them.

\section{METHODS}

This study was carried out concerning the house-breaking victims selected from nine districts in Sri Lanka. Figure 2 indicates the number of cases selected from each district. From each district, a number of victims from 5 to 9 were chosen from a convenient sample drawn from the data available in selected police stations. Selected victims were met at their houses and the data were collected by interviewing them using an interview schedule. Interviews were designed primarily to gather data on the impacts of house-breaking on the victims, the nature of the incidents, and the criminals' motives that drive them to steal from people. This semi-structured open-ended procedure took approximately forty minutes per victim. However, the length of the interview was subject to a considerable individual variation. An assurance of confidentiality and voluntary nature of participation were established with those who participated in the interviews.

Figure 2: Sample units selected from each selected district

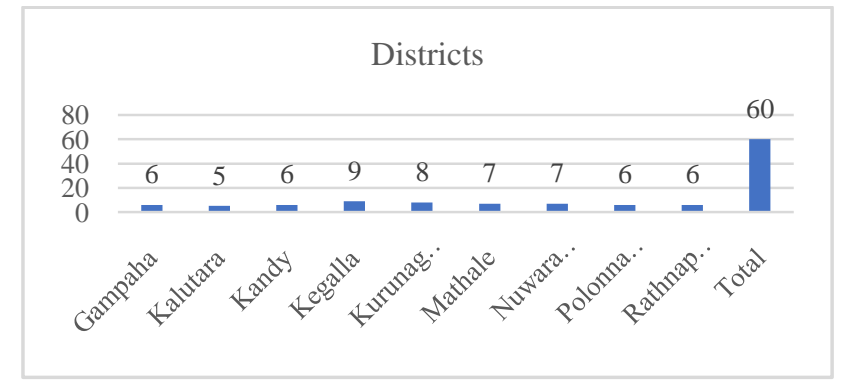

Source: Field Research 2019

In this study, both qualitative and quantitative data were collected regarding the impacts of house-breaking on victims and the behaviour of the house-breakers. In analyzing data, standard data analysis methods were utilized to achieve the objectives of the study.

Figure 3: Gender of the Victims of House-breaking

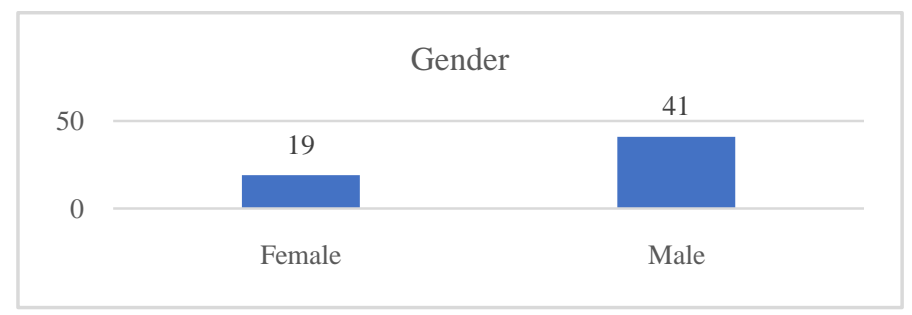

Source: Field Research 2019

Although male dominance is well evident in the commission of house-breaking, its victimization indicates that the majority of the victims were predominantly of a male target-oriented crime. The reason is obviously that in most households the entire family has become the victims because the head of the family is often a male and he represents the victims of the 
family. According to Figure 3, over 68.3\% of house-breaking victims are males. This figure suggests that house breakers do not consider any risk resistance from males as head of the residence in perpetrating their crime. However, $31.7 \%$ of females have also been the victims of housebreaking in the study as they have played the role of head of the household in the absence of their husbands.

\section{DATA ANALYSIS AND FINDINGS}

Figure 4. Age distribution of the victims of House-breaking

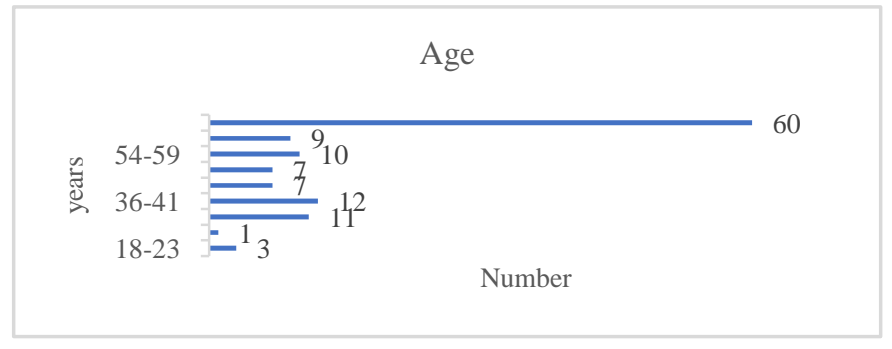

Source: Field Research 2019

The present study was conducted on 60 victims of housebreaking selected from nine police stations in different districts of Sri Lanka. Their age distribution indicates an extensive age range in Figure 4. Accordingly, the highest number of victims i.e., 12 of them (20\%), belong to the age group of 36 to 41 years. The second highest group numbering 11 victims (18.3\%) represent the age group between 30 to 35 years. However, the youngest belong to the age group of 18 to 23 years and they stand numerically at $3(5 \%)$. The age categories of victims between $42-47$ and 48-53 years represent 7 victims $(11.7 \%)$ each. The age category of between 54-59 represents $10(16.7 \%)$ victims. The least number of victims includes in the age group of 24-29 which amounts to only one. Further, nine individuals (15\%) of the victims in the age group above 60 years have also been victimized by the house breakers and it is indeed a pathetic situation as people of such age remain dependent on others for their protection and survival. Targeting the elderly indicates that the crime of housebreaking has assumed brutal proportions. As Conklin (1972) mentions "When burglars have opportunities to select the targets they often prefer to choose victims who are elderly, female and alone", and this consistent with the present study too.

Figure 5. The religion of the Burglary Victims

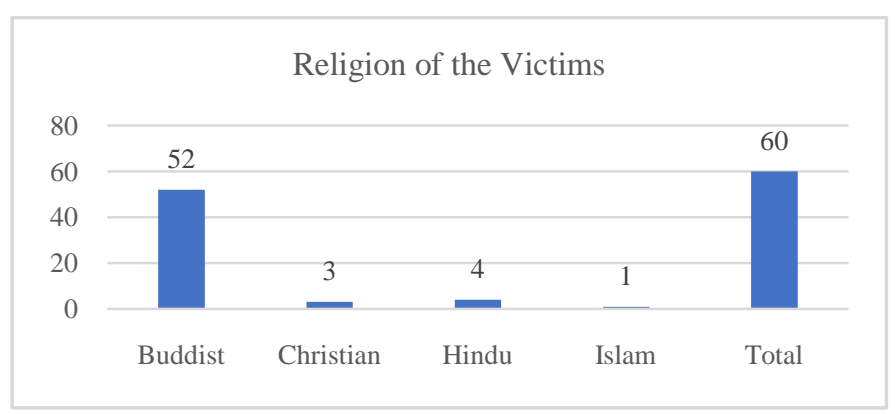

Source: Field Research 2019
Among the individualistic factors that affect housebreaking, the religion of the victims seemed significant for it indicates that the majority $52(86.7 \%)$ of the victims selected in the sample were the Buddhists. The reason for this was that the majority of housebreakers were mainly Buddhists and they preferred to break into houses of the people that belong to the same culture. As Figure 5 indicates, the second-highest group of 4 victims $(6.7 \%)$ comprised the Hindus, and $3(5 \%)$ the Christians while one victim was from Islam.

Figure 6 - Position of Housebreaking Victims

\section{Position of Victims}

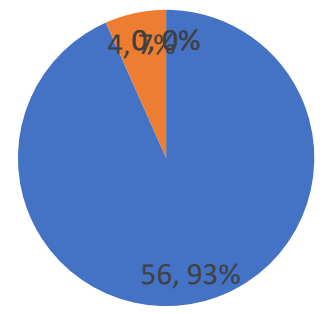

Source: Field Research 2019

In the present study, 56 victims (93\%) were the primary victims of housebreaking incidents. They have faced the incidence directly and therefore had the first-hand experience of becoming victims in housebreaking. The rest $4(7 \%)$ were the family members and secondary victims of the incidence of housebreaking.

Figure 7: Educational Standard of the Housebreaking Victims

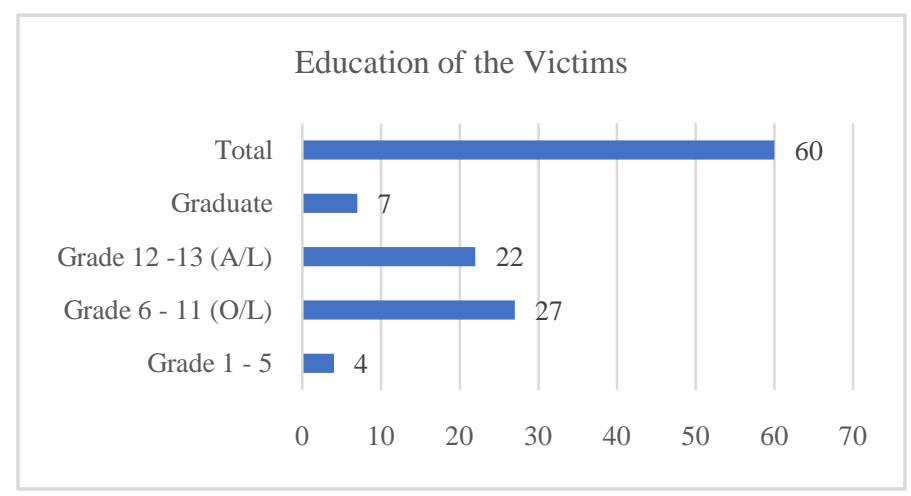

Source: Field Research 2019

Figure 7 shows the standard of education of housebreaking victims. The educational level of victims is a vital factor in understanding the social phenomenon of housebreaking victimization. Compared to the victims of other crime categories as murder and rape, the education of housebreaking victims remains at a higher standard. Accordingly, 11.7\% $(n=7)$ of the victims have obtained degrees from universities and $36.7 \%(\mathrm{n}=22)$ have studied up to General Certificate of Education (Advanced Level). In comparison, 45\% ( $n=27)$ of victims have studied up to General Certificate of Education (Ordinary Level) to a lesser grade and extent $6.7 \%(n=4)$ of 
them had only grade five or lesser education. It was revealed that the victims had mostly faced the housebreaking incident unexpectedly with violence.

Figure 8: Civil Status of the Victims of Housebreaking

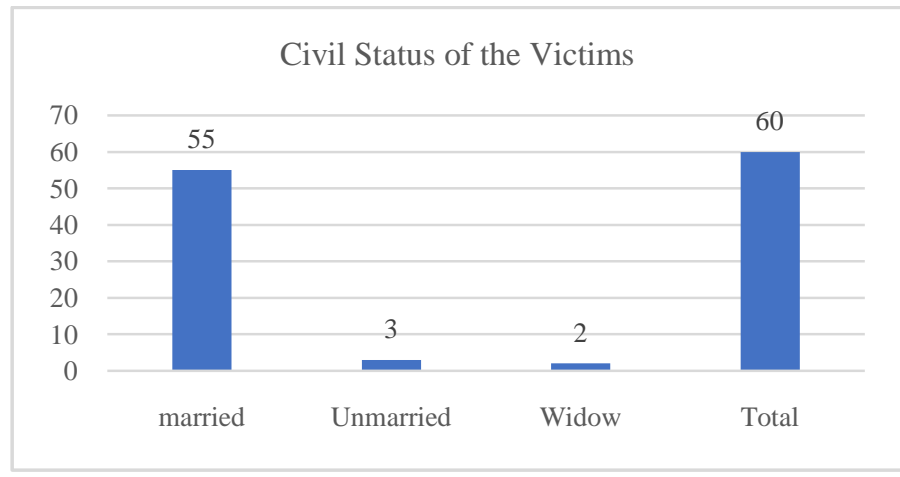

Source: Field Research 2019

\section{Civil Status of the Victims}

According to Figure 8, the marital status of the victims can be interpreted as follows. $91.7 \%$ of the victims $(n=55)$ were married while $5 \%(n=3)$ were unmarried. There were two widows $(3.3 \%)$ in the study. It is worth noting that many married families werestable and often owned a house with properties accumulated for their living.

Figure 9: Career of the Victims of housebreaking

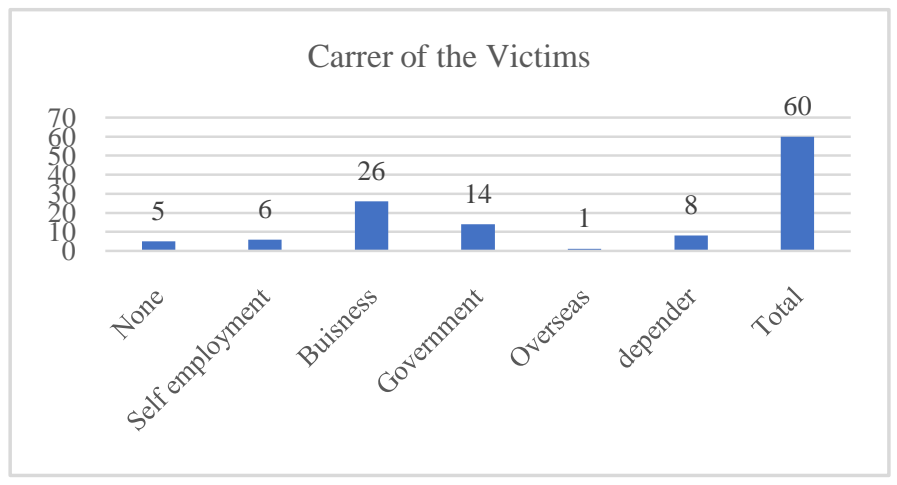

Source: Field Research 2019

A particular pattern of target selecting for the commission of housebreaking is quite evident from the employment information of housebreaking victims. According to Figure 9, only $23.3 \% \quad(\mathrm{n}=14)$ victims were government sector employees at the time of the crime was committed. Over $10 \%$ $(n=6)$ were self-employed and the majority $43.3 \% \quad(n=26)$ victims were engaged in their businesses and such people are considered comparatively wealthier than the others in the society. Accordingly, 78.3\% ( $\mathrm{n}=47)$ of housebreaking victims were people having medium and high-income level. It is also noteworthy that nearly $8.3 \%(n=5)$ of victims were without any employment, and the rest $13.3 \%(n=8)$ of the victims were dependent on their families as the family had enough income to maintain the lives of its members.
Figure 10: Income of the Victims of Housebreaking

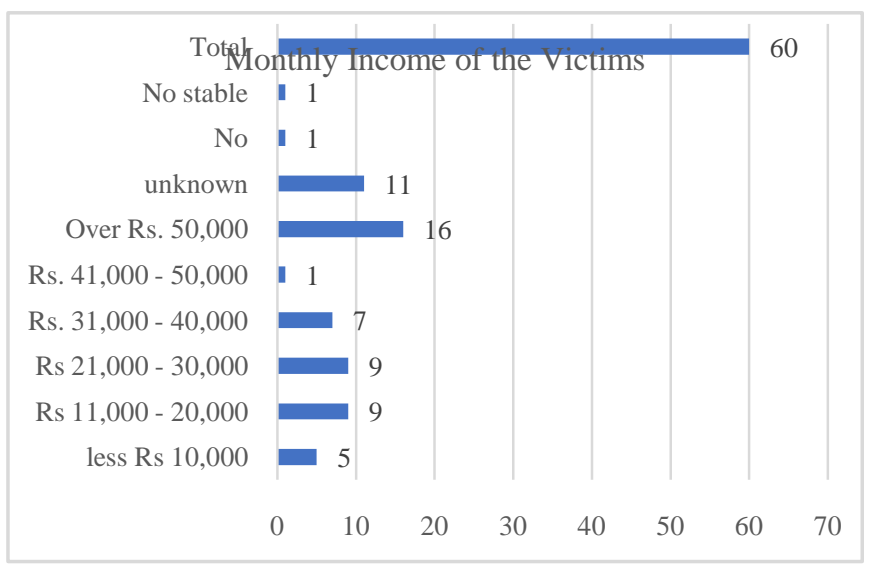

Source: Field Research 2019

Even though one housebreaking victim (1.7\%) stated that he was unemployed, $11(13 \%)$ victims were not willing to mention their exact monthly income. In Sri Lanka, it is a common practice that higher-income earners mainly businessmen do not like to reveal their income as it would adversely affect them in dealing with tax officers, beggars and other charity seekers. Only five victims had received less than 10,000 rupees as their monthly income, and the rest of the victims of housebreaking had received a monthly income of Rs. 11,000 to 50,000 while 16 (26.7\%) victims had received over 50,000 rupees of monthly income. Therefore, it is believed that the perpetrators had perceived all their victims were wealthy enough to be burglarized.

Figure 11: Time of the Housebreaking

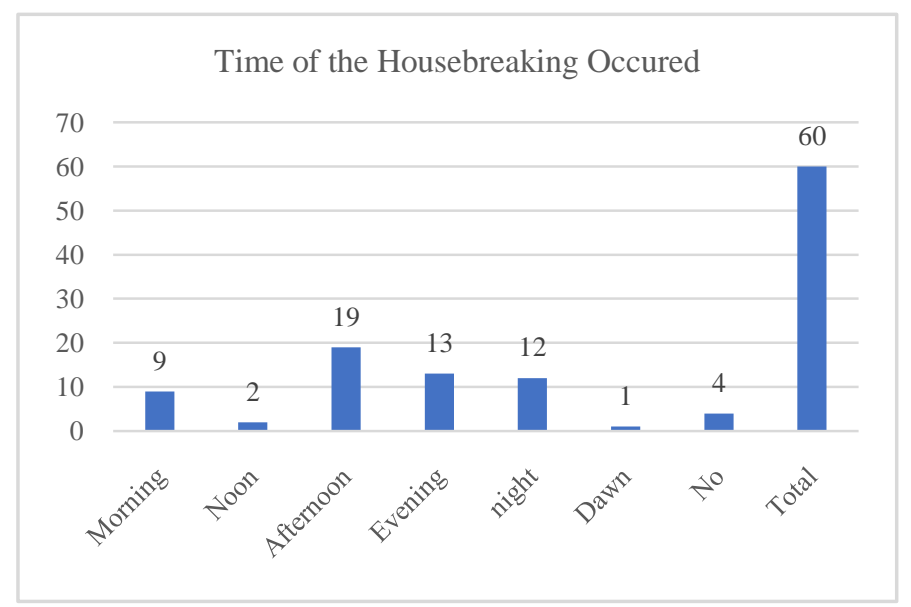

Source: Field Research 2019

Criminologist have discovered that time is a significant factor for housebreakers owing to several reasons specially to minimize the time spent on target places to hide their intention. The opportunity for burglary occurred only when dwelling is unguarded and completion of burglary within their working hours like legitimate employee clock off in a fix time (Adler, F. et.al. 1995:277). The time of the occurrence of housebreaking was also a concern of the present study. Figure 11 shows that most of the incidents $(31.7 \%, \mathrm{n}=19)$ have taken 
place in the afternoon. The number of housebreaking committed in the morning has remained up to $15 \%(n=9)$ as people are either asleep or they have left their homes in the early morning to arrive at their workplaces. Further, only a few stays at home during the morning and housebreakers take this opportunity to steal valuables from houses. Further, as the time of the occurrence of the house-breaking is concerned $21.74 \%(n=13)$ of the housebreaking had occurred in the evening while $20 \%(n=12)$ of the incidents at night after people have gone to bed. Only one incident of housebreaking had occurred at dawn when occupants quitted their homes.

Figure 12: Place of the housebreaking Occurred

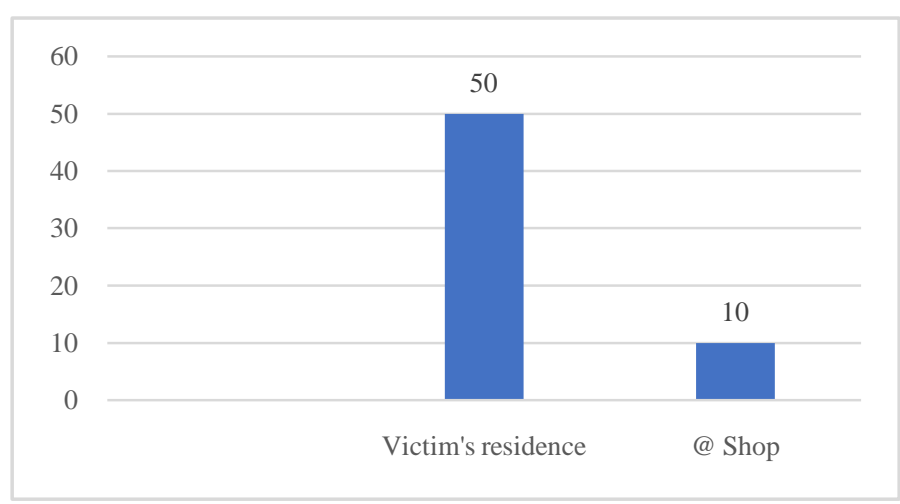

Source: Field Research 2019

The selection of places for housebreaking is also a critical factor. The housebreakers are concerned with the familiarity of the area, fear of recognition and concern over 'standing out' as someone who does not belong there. (Adler, F. et.al. 1995:277). The causation of crime against humans takes place due to multiple reasons. As a social being, an individual who interacts with the other members of the society may experience criminal activities, especially with the people in his/her community and outside. When people have unfulfilled requirements and economic hardships and fail to satisfy them in socially and culturally accepted ways, some adopt illegal methods to fulfil their needs. Consequently, some criminals use different methods to acquire money and valuables from the houses where the least resistance is shown and they also make use of the places where they can rob others without much threat. As Figure 12 shows, 50 persons (83.3\%) had been victimized at their own houses while the rest of the incidents $(16.7 \%)$ had occurred in outside places such as commercial establishments and shops located in isolated places where opportunity permitted the thieves to steal money and other valuables. As Conklin (1986) explains when burglars select their targets, they consider unoccupied houses and business establishments, non-availability of security measures, availability of valuables and inconspicuous settings.

Table 2. Nature of the Housebreaking

\begin{tabular}{|c|c|c|}
\hline Nature & Frequency & $\boldsymbol{\%}$ \\
\hline Steal money alone & 08 & 13.3 \\
\hline Steal money and golden ornaments & 31 & 51.7 \\
\hline
\end{tabular}

\begin{tabular}{|c|c|c|}
\hline Steal electronics and other items & 18 & 30 \\
\hline Stealing was not materialized & 03 & 5 \\
\hline Total & 60 & 100 \\
\hline
\end{tabular}

Source: Field research 2019

The nature of the robbery was a primary concern in the study. It was revealed that $31(51.7 \%)$ incidents were connected with stealing money and golden ornaments belonging to both males and females. In Sri Lankan society, gold is considered an asset of wealth and therefore people wear valuable golden ornaments not only as a passion but also to display their social status. The females often wear golden jewelry to enhance their beauty and also to exhibit their wealth. Males also wear gold as chains, bracelets, rings etc. to show off their wealth. Accordingly, the stealing of golden chains and ornaments has become the main target of many house-breakers and they can easily convert gold into money through fences or pawnbrokers. Apart from that, some house-breakers were keen on stealing different household items such as electronics, mobile phones, and other valuable items which could be converted into money quickly and easily.

Figure 13: Victim's Relationship to Burglar

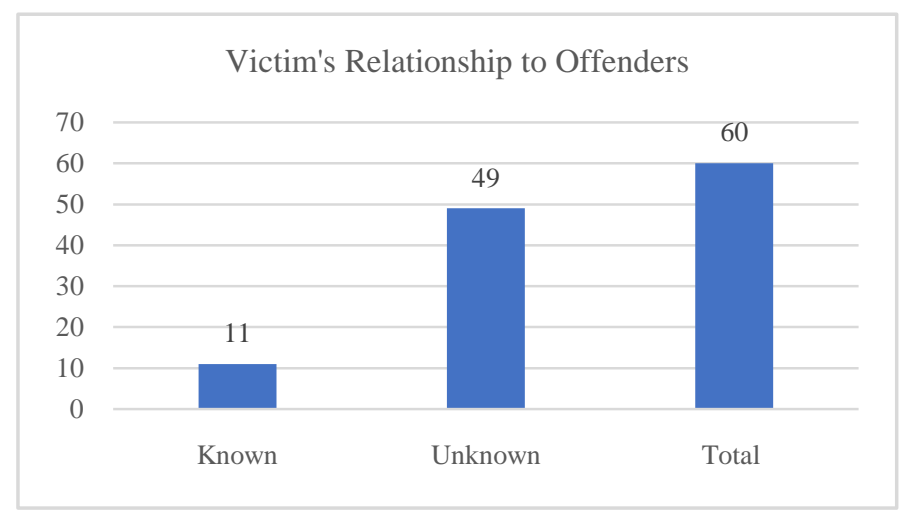

Source: Field Research 2019

As the relationship between offender and victim is concerned, the majority of offenders $n=49(81.7 \%)$ were not known to the victims and this can be considered as a typical characteristic of housebreaking. However, the study reveals that about $n=11$ $(18.3 \%)$ of the offenders had been known to the victims while many of them were their neighbors. This particular relationship should be understood from the social context of the victims and the offenders. As the study reveals, housebreaking is not a crime confined to the unknown and strange offenders. There are also known offenders who have strategically perpetrated housebreaking against their communities and families. According to Figure 13, relatives and neighbors were included among the offenders who had been involved in committing burglary within their own community. This factor appears as a controversial pattern in criminal behavior. When such cases are studied, these relationships can be understood in detail. For example, in cases where relatives are rich and have refused to offer their close relatives financial assistance, in retaliation, they have 
organized housebreaking against the relatives who refused them money in a very tricky and subtle manner.

Table 3: Addictive behaviour of the House-breakers

\begin{tabular}{|c|c|c|}
\hline Nature of the Addictive behaviour & Frequency & $\boldsymbol{\%}$ \\
\hline Alcohol use & 10 & 16.7 \\
\hline Drugs and Alcohol use & 08 & 13.3 \\
\hline Unknown & 42 & 70 \\
\hline Total & 60 & 100 \\
\hline
\end{tabular}

Source: Field Research 2019

The findings of the study reveal that the house-breakers have frequently taken to alcohol and drugs, and at the time that they committed house-breaking, some are known to have been under the influence of alcohol and drugs or either of them. In general, the consumption of alcohol and drugs are deemed to stimulate or facilitate the criminal behaviour of the perpetrators and influence them to lower their inhibitions, impair judgements, and increase their recklessness and risktaking behaviour. Substance abuse and its relationship to crime may vary according to the factors such as the amount and the type of substance consumed, the background and the personality of the user, and the social situation in which the substance is used. Table 3 indicates that $30 \%$ of the housebreakers used to take either alcohol or drugs or both, while $70 \%$ of victims of house-breaking had not known whether house-breakers had taken drugs or alcohol at the time of the commission of the robbery. Among the criminals, there were $13.3 \%$ of house-breakers who had taken to heroin. It is noteworthy here that the heroin addicts often used black money illegally to purchase their daily consumption of drugs at street prices. According to the research conducted on alcohol and drug use, they had different effects on different people and even on the same person. It is acknowledged that after taking a small amount of alcohol, most people will experience cheerful feelings while taking moderate or large amounts of alcohol, they tend to develop aggressive and violent behaviour patterns as alcohol consumption impairs judgements, lowers frustration tolerance, and induces disinhibition (Curran and Renzetti, 1994:122). Within this scenario, it can be assumed that some offenders carry out house-breaking to find money for drugs and alcohol. Especially, heroin addicts need over three thousand rupees for their daily consumption of heroin, and they often earn this amount through the commission of property crimes including housebreaking.

Table 4: The impacts of the incidence of Housebreaking on victims

\begin{tabular}{|c|c|c|}
\hline The impacts on victims & Frequency & \% \\
\hline Financial loss & 50 & 83.3 \\
\hline Economic hardship & 06 & 10 \\
\hline Anxiety about house-breaking & 04 & 6.7 \\
\hline Total & 60 & 100 \\
\hline
\end{tabular}

Source: Field Research 2019
The present study was concerned about the impact of the incidence of housebreaking on the victims. As Table 4 indicates, $50(83.3 \%)$ victims said that they suffered from financial loss as their houses were broken and cash and valuables were stolen. Another six victims declared that they sustained physical injury with the assault of housebreakers in addition to loss of their cash and valuables. Another $3(n=6.7)$ stated that they did not experience any financial loss as they were able to catch the offenders after they had entered the house. However, four victims declared that they experience anxiety regarding housebreaking while many others $(n=50)$ accepted that they suffered from great psychological impact of their house being broken.

The study revealed that burglars had entered ten business establishments, ranging from minor scale to medium scale, and stolen money and other valuable items which were on sale. Perpetrators had found it easy to enter the shops by breaking windows or scaling over and rooftops in the absence of any person in those commercial establishments during the night.

According to the research findings, it was revealed that many victims of house-breaking had changed their lifestyles after their gruesome experience. They had changed their behavioural patterns so as to prevent them from being revictimized in future. Table 5 indicates the way that the victims of house-breaking had changed their lifestyle to cope up with revictimization.

Table 5: The Behavioral Changes of Victims after their Victimization

\begin{tabular}{|c|c|c|}
\hline Type of Change & Frequency & $\%$ \\
\hline Deposit Golden Ornaments in a Bank & 3 & 5 \\
\hline Fixing Grills for windows & 4 & 6.7 \\
\hline $\begin{array}{c}\text { Stay in the house during the night or keep } \\
\text { someone at home in the absence of occupants }\end{array}$ & 3 & 6.7 \\
\hline Fixing CCTV cameras & 4 & 5 \\
\hline $\begin{array}{c}\text { Keeping no valuables in the night at } \\
\text { commercial establishments }\end{array}$ & 1 & 6.7 \\
\hline Changed the residence & 41 & 68.3 \\
\hline Keep special vigilance on their homes & 60 & 100 \\
\hline Total & & \\
\hline
\end{tabular}

Source: Field Research 2019

Some victims of house-breaking said that they had to give up their habits and routine activities to prevent themselves from falling into revictimization. For example, three (5\%) victims declared that they deposited their golden ornaments in a bank to prevent them from being re-burglarized. Another four $(6.7 \%)$ stated that they fixed grills to their house windows so as to prevent them from re-broken. The opinion of another four $(6.7 \%)$ victims was that they stayed in their homes especially at night and in their absence, they would keep another person for the protection of their house. Another three victims had set up CCTV cameras in their houses as a way of identifying any burglar entering the house. However, four $(6.7 \%)$ owners of the commercial establishments said that 
they did not keep the valuables in their shops at night. One family had changed their residence as their house had been burglarized on their wedding day and it was considered a bad omen for the bride who made the first visit to the bridegroom's home. Consequently, they had changed their residence to escape from the possible ill-effects. However, the majority mentioned that they maintained vigilance on their premises after their houses were broken.

\section{Case Study 1}

The incident has occurred in Minuwangoda in Gampaha district. When occupants of the house were asleep in the night, burglars had entered the house breaking the lock on the back door. They had stolen goods valued over 40,000 rupees. The following day the morning the occupants of the house had come to know about the burglary and the subsequent loss of cash. Thus, they made a complaint at the nearest police regarding the incident. Later the police have investigated the housebreaking but so far the stolen property has not been recovered. The head of the household explained that in his residential area narcotic drugs kept spreading exponentially. Those who have taken to drugs commit house-breaking to find money that they require to finance drugs. Although the residents of the area have made the police aware of this matter, so far, the police have not been successful in curbing the narcotic drug menace in the area. The residents of the area opinionated that the police should be made to be more aware about their duties and they be directed to curb such property crimes.

\section{Case 2.}

Cyril a carpenter who was the owner of the house had gone with his family members to participate in a religious ritual held at night in a house located in his residential area. On that occasion, housebreakers had entered his house and stolen the gold ornaments and valuable equipment that he used for the performance of his job, carpentry. Having logged a complain with the police, they have the authorities have investigated the housebreaking and they have found a suspect connected with the incident. After the suspect was produced at the court, the police were not able to produce sufficient evidence against him and the court has dismissed the case and released the suspect.

As a poor carpenter, he was not able to find the stolen equipment needed for carrying out his profession. He has frustration about the loss of his equipment.

\section{Case 3}

This incident has occurred at Mudungoda in Gampaha district. The victim is a retired teacher a widow. When she was not at home two burglars had entered the house breaking a window and stolen golden ornaments and electronic equipment. These two perpetrators were drug addicts and they had stolen the valuables to find money to buy narcotics for their consumption. A neighbor had informed the police about this incident on 119 telephone line. Consequently, the police had investigated the incident and arrested two offenders and produced them at the court. The court had ordered the offenders to return the stolen property to the victim with a compensation. The victim has received the stolen property with some compensation. At present, as drug addicts still surround the area the victim fears revictimization.

\section{Case 4}

This incident has occurred to a 29-year old bride in Gampaha. On the eve of her wedding day, she had been accompanied by the bridegroom to his home at Mandadeniya in Kuruwita. On that fateful day when people at home were busy with the wedding preparations and burglars had entered the house and stolen the bride's jewelry and cash valued at Rs. 300.000. According to belief of the villagers the bride brings forth fortune to the house of bridegroom after her marriage. However, the opposite has occurred to the bridegroom's house and the villagers were of the views that it was a bad omen for the bridegroom and his family. This situation has thrown the bride into total confusion and she became scared and frustrated and eventually, the family moved out to settle down in another village in a remote area. So far neither the stolen property has been discovered nor the offenders have been identified.

The above four case studies expose the causes of housebreaking and the nature of the and burglars. Correspondently, all the victims have faced burglary. Some incidents of housebreaking have occurred in the absence of occupants at their homes whereas some other events have taken place when the intimates were asleep after their scheduled work of the day. The victims were aware that their property was often stolen by drug addicts to finance the daily requirements of narcotics. Some victims blamed the police that they did not work either to minimize or eradicate the drug menace in their area. The victims thought that the housebreakers could have caused physical harm to them if they were at home and made any resistance to housebreaking.

\section{CONCLUSIONS}

This study was aimed at conducting research on the "impacts of housebreaking on the victims and their attitudes after victimization". The nature of the victim of housebreaking was a concern in the study. Accordingly, data were gathered and analyzed in line with the objectives of the study and the following conclusions were drawn.

The present study revealed that the highest number of victims $(n=12 ; 20 \%)$ belonged to the age group of $26-41$ years. The second highest group $(\mathrm{n}=11 ; 18.3 \%)$ represented the age group of 30-35 years. Further, three of the victims were the youngsters belonging to the age group of 18-23 years. Each category of age group 42-47 and 48-53 years represented seven $(11 \%)$ victims while the least number i.e., one victim belonged to the age group of 24-29 years. According to the study, a quite lot of elderly people above 60 years numbering $9(15 \%)$ have become the victims of housebreaking. This situation seems indeed pathetic as the elderly remain mostly 
dependent on others for their protection and survival. The causes for victimization were also considered in the study, and it was revealed that a low standard of education was not actually an essential contributory factor to become a robbery victim. Correspondently, almost half of the victim population (48.3\%) had studied up to Advanced Level or above while the other $45 \%$ of the victims had obtained a standard of education between grade 6 and grade 11 . Of the total number only $6.7 \%$ of the victims had received education between grade 1 to 5 . only the between grade 1-5 education. The majority of victims (86.7\%) represented the Buddhists, while $6.7 \%$ were Hindus, 5\% were Christians and the rest (1.6) were Islamic. The highest number of the victims $(91.7 \%, \mathrm{n}=55)$ in the sample were married and 5\% ( $=3)$ were unmarried while $3.3 \%(\mathrm{n}=2)$ were widowed.

In comparison with the other form of property crime such as robbery, housebreaking has often been committed without any physical harm to the victims. The reason was that many housebreakings had been committed in the absence of the occupants of their houses or commercial establishments. In the rest of the cases, occupants of houses were asleep at the time of housebreaking. However, four burglars have been caught by the occupants at the time they entered the house. As the gender is concerned, housebreaking is predominantly carried out by males and they account for $100 \%$ of the incidents of house-breaking when compared to the other maledominant grave crimes. The link between the victims and the housebreaker indicate that most of the burglars $(81.7 \%)$ were unknown to the victims whereas the rest $18.3 \%$ of the burglars were known to the victims and of them, $13 \%(n=6)$ were relatives of the victims. It was revealed that those known housebreakers had strategically carried out the housebreaking against their relatives and the members of their own community.

A particular pattern in selecting their targets for the commission of housebreaking was quite evident from the employment information of the victims of housebreaking. Accordingly, $43.2 \%$ of the victims were businessmen whereas only $23.2 \%$ of victims worked in the State sector. These categories of employees were either medium or high-income earners while $10 \%$ of the victims were self-employed and they too had considerable income as compared to the others in the community. Therefore, it is obvious that housebreakers target those people who keep money or other valuables at their houses. As the nature of the housebreaking was concerned, the study found that housebreakers main concern was cash and therefore, they had stolen only money in $13.3 \% \quad(n=8)$ incidents of housebreaking. Further, housebreakers were keen on stealing valuables that can be easily converted to money. Consequently, 31 incidents (51.7\%) involved stealing money and golden ornaments, and in $30 \%$ of the incidents, housebreakers had stolen valuable household items such as electronics, mobile phones, televisions etc. In one incident, housebreakers had taken away the tools of a carpenter.

Even though house-breaking remains a complex social phenomenon, the study inquired into the general perception of the victims about the causes that led offenders to commit housebreaking. Accordingly, 18 offenders (30\%) had committed housebreaking to finance their habit of taking alcohol and drugs when other avenues for finding money appeared very remote to them. The rest of the incidents of housebreaking were believed to have been committed due to their poverty stricken conditions and other urgent financial requirements as an easy way of earning money.

The impact of the incidence of housebreaking on victims was also a primary concern in the study. It was revealed that 93.3\% of the victims suffered from economic loss and 6.7\% declared that they experienced anxiety and mental pain caused by the housebreaking as they constantly imagined revictimization. Some victims expressed that they had to undergo severe economic hardships as criminals stole their valuables. Most of the victims stated that they had to change their normal behaviour patterns in their lives. Accordingly, four $(6.7 \%)$ victims had fixed up CCTV Cameras in their homes for fear of being victimized again. Another three (5\%) victims stated that they did not go out at night and often tried to stay at home or in case of their absence they always took measures to keep someone at home until they got back home. Still other three victims (5\%) declared that they fixed grills for their broken windows to prevent burglary. Another two victims involved in the business activities said that they did not keep valuables in their shops at night.

The study proposes that the rate of housebreaking can be reduced in Sri Lanka by persuading people to protect themselves and also by using situational crime prevention techniques. From the perspective of law enforcement, the police can help the people by providing more security to them, especially in different geographical areas where housebreaking has been rampant. frequently occurred. Furthermore, police should take adequate measures to minimize the number of people who have taken to drugs and alcohol as they often tend to commit housebreaking to find the required money for drugs and alcohol. Apart from that, the police should effectively make use of prevailing retributive punishments to deter criminals who are involved in housebreaking.

\section{REFERENCES}

[1] Adler, F., Mueller, G.O.W., Laufer, W.S. (1995) Criminology. New York: McGraw-Hill, Inc.

[2] Barlow, H. D. (1978) Introduction to Criminology. Toronto: Little Brown and Company.

[3] Conklin, J.E. (1972) Robbery and the Criminal Justice System. Philadelphia: Lippincott.

[4] Conklin, J.E. (1986) Criminology. New York: Macmillan Publishing Company.

[5] Curran, D.J., Renzetti, C.M. (1994) Theories of Crime. USA: Allyn and Bacon

[6] Decker S., Wright, R., Redfern, A., Smith, D., “ A Woman's Place in the Home: Females and Residential Burglary," Justice Quarterly, 10 (1993): 143-162

[7] Mawby, R. (2021) Burglary. Colompton, Devon:Willan

[8] Mullins, C., Wright, R. (2003) Gender, social networks, and residential burglary. Criminology, 41, 813-839.

[9] Paranjape, N.V. (2011) Criminology and Penology with Victimology. Allahabad: Central Law Publication. 
[10] Penal Code of Sri Lanka (1883) Colombo: Ceylon Government Press.

[11] Rengert, G., Wasilchick, J. (2000) Suburban burglary: A tale of two suburbs. Springfield, IL: Charles C Thomas.

[12] Reports of the Inspector General of Police, Sri Lanka 2001-2019.
[13] Shover, Neal (1972) "Structures and Careers in Burglary", Journal of Criminal Law and Criminology, 63 (1972) 540-549

[14] Wales, A., Hemmens, C. (2011) Introduction to Criminology. USA: Sage Publication Inc.

[15] Wright, R., Decker, S. (1994) Burglary on the Job: Streets and residential break-ins. Boston: Northeastern University Press. 